\title{
BMJ Open Multicountry survey of emergency and critical care medicine physicians' fluid resuscitation practices for adult patients with early septic shock
}

\author{
Lauralyn Mclntyre, ${ }^{1,2,3}$ Brian H Rowe, ${ }^{4,5}$ Timothy S Walsh, ${ }^{6}$ Alasdair Gray, ${ }^{7}$ \\ Yaseen Arabi, ${ }^{8}$ Anders Perner, ${ }^{9}$ Anthony Gordon, ${ }^{10}$ John Marshall, ${ }^{11}$ \\ Deborah Cook, ${ }^{12}$ Alison Fox-Robichaud, ${ }^{13}$ Sean M Bagshaw, ${ }^{14}$ Robert Green, ${ }^{15}$ \\ Irwin Schweitzer, ${ }^{2}$ Alexis Turgeon, ${ }^{16,17}$ Ryan Zarychanski, ${ }^{18}$ Shane English, ${ }^{1,2,3}$ \\ Michaël Chassé, ${ }^{2,3}$ Ian Stiell, ${ }^{2,3}$ Dean Fergusson, ${ }^{2,3}$ for the Canadian Critical Care \\ Trials Group
}

To cite: McIntyre L, Rowe BH, Walsh TS, et al. Multicountry survey of emergency and critical care medicine physicians' fluid resuscitation practices for adult patients with early septic shock. BMJ Open 2016;6:e010041.

doi:10.1136/bmjopen-2015010041

- Prepublication history and additional material is available. To view please visit the journal (http://dx.doi.org/ 10.1136/bmjopen-2015010041).

Received 26 January 2016 Revised 22 April 2016 Accepted 3 June 2016

CrossMark

For numbered affiliations see end of article.

Correspondence to Dr Lauralyn McIntyre; Imcintyre@ohri.ca

\section{ABSTRACT}

Objectives: Evidence to guide fluid resuscitation evidence in sepsis continues to evolve. We conducted a multicountry survey of emergency and critical care physicians to describe current stated practice and practice variation related to the quantity, rapidity and type of resuscitation fluid administered in early septic shock to inform the design of future septic shock fluid resuscitation trials.

Methods: Using a web-based survey tool, we invited critical care and emergency physicians in Canada, the UK, Scandinavia and Saudi Arabia to complete a self-administered electronic survey.

Results: A total of 1097 physicians' responses were included. $1 \mathrm{~L}$ was the most frequent quantity of resuscitation fluid physicians indicated they would administer at a time $(46.9 \%, \mathrm{n}=499)$. Most $(63.0 \%, n=671)$ stated that they would administer the fluid challenges as quickly as possible. Overall, normal saline and Ringer's solutions were the preferred crystalloid fluids used 'often' or 'always' in $53.1 \%(n=556)$ and $60.5 \%(n=632)$ of instances, respectively. However, emergency physicians indicated that they would use normal saline 'often' or 'always' in $83.9 \%(n=376)$ of instances, while critical care physicians said that they would use saline 'often' or 'always' in $27.9 \% \quad(n=150)$ of instances. Only $1.0 \%(n=10)$ of respondents indicated that they would use hydroxyethyl starch 'often' or 'always'; use of $5 \%(5.6 \%(n=59))$ or $20-$ $25 \%$ albumin $(1.3 \%(n=14))$ was also infrequent. The majority $(88.4 \%, n=896)$ of respondents indicated that a large randomised controlled trial comparing $5 \%$ albumin to a crystalloid fluid in early septic shock was important to conduct.

Conclusions: Critical care and emergency physicians stated that they rapidly infuse volumes of $500-1000 \mathrm{~mL}$ of resuscitation fluid in early septic shock. Colloid use, specifically the use of albumin, was infrequently reported. Our survey identifies the
Strengths and limitations of this study

- This survey included a large sample of emergency and critical care physicians' stated early septic shock resuscitation practices from Canada, the UK, Scandinavia and Saudi Arabia.

- The survey was designed to be short, simple and specific to the early resuscitative phase of septic shock so that it would take at most 5 min to complete.

- Since the survey focused on the early resuscitative phase of septic shock, the responses to questions may not be generalisable to later phases of septic shock or specific subpopulations of patients with septic shock.

- Owing to the variable methods used for survey distribution, we could not summarise an accurate response proportion.

need to conduct a trial on the efficacy of albumin and crystalloids on 90-day mortality in patients with early septic shock.

\section{BACKGROUND}

Fluid resuscitation is a vital first-line intervention for all patients with septic shock. Management guidelines recommend rapid administration of resuscitation fluid to achieve a minimum of $30 \mathrm{~mL} / \mathrm{kg}$ in the early hours of resuscitation, with the goal of regaining haemodynamic stability, optimising organ perfusion and ultimately improving outcomes and preventing death. ${ }^{1}$ While fluid resuscitation is a life-saving intervention, until recently, high-quality evidence to guide fluid choice and resuscitation practices has been lacking.

In recent years, there has been an accumulation of evidence regarding fluid resuscitation 
that has served both to change practice and prompt further resuscitation research questions. For example, a multicentre paediatric trial from East Africa of predominantly malaria-infected children with severe fever and hypoperfusion questioned how aggressively we should administer resuscitation fluids in this setting. ${ }^{2}$ This trial found that fluid boluses, as compared with the administration of intravenous maintenance fluids, increased the risk of death at 48 hours. The results of these research findings have encouraged other investigators to further study aggressive versus conservative fluid resuscitation strategies for children and adults with septic shock in the emergency department (ED) and intensive care unit and clinical trials are ongoing or recently completed (Clinical Trials.gov NCT02079402 and NCT01973907, respectively). Evidence has also emerged to help guide practice with regard to the use of colloid fluids in sepsis. In 2004, our group conducted a survey of early septic shock resuscitation practices of Canadian critical care physicians and found that hydroxyethyl starch (HES) fluid was used commonly, reportedly $51 \%$ of the time. ${ }^{3}$ An international cross-sectional study of fluid resuscitation episodes in the intensive care unit conducted in 2007 also documented frequent colloid fluid use (48\% of episodes) and $44 \%$ of colloids administered were HES fluids. ${ }^{4}$ Since the publication of these studies, data from randomised trials and systematic reviews have demonstrated clear harms caused by HES in critically ill patients, particularly those with sepsis. ${ }^{5-9}$ Although a recent systematic review of albumin in sepsis found no overall mortality benefit, ${ }^{10}$ two subgroup analyses from recent randomised trials comparing albumin to crystalloid fluid in the critically ill and severe sepsis and septic shock found reductions in mortality at 28 and 90 days, respectively. ${ }^{11} 12$

In the context of evolving literature to guide practice, we conducted an early septic shock fluid resuscitation survey to inform the design and provide justification for future early septic shock fluid resuscitation trials comparing 5\% albumin versus crystalloid fluid on 90-day mortality. Our survey had two objectives: (1) to describe practice variation among emergency and critical care physicians regarding the quantity, rapidity and type of fluid administered during early septic shock resuscitation and (2) to elicit views of a future early septic shock fluid resuscitation trial comparing $5 \%$ albumin versus crystalloid fluid on 90-day mortality by eliciting from respondents the minimal clinically important difference (MCID) between fluid intervention and control arms that would inform their practice, as well understanding the perceived importance of and respondents' willingness to enrol into such a future trial.

\section{METHODS}

Identification of study participants and survey distribution

Our target population consisted of critical care and emergency physicians in Canada, the UK, Scandinavia and Saudi Arabia who provide care for adult patients
( $\geq 18$ years of age) with septic shock. These countries were selected because research and opinion leaders in these countries had expressed interest in collaborating on an international trial on early fluid resuscitation.

Participants were contacted by their respective critical care or emergency medicine professional societies in the UK and Canada, and through direct contact with lead site investigators in Canada, Scandinavia (including the countries Norway, Sweden, Finland and Denmark) and Saudi Arabia using a standardised email containing a weblink to the survey. Respondents activated the weblink and completed the survey instrument online. The survey was distributed in January and February 2014. To maximise responses, non-respondents received up to two email reminders.

\section{Survey development}

We generated items for the survey instrument through literature review and consultation with international investigators representing emergency and critical care medicine. Items were reduced and formatted to reduce respondent burden and maximise the response rate. The survey was pilot tested by our investigative team and critical care research fellows at the University of Ottawa in Ottawa, Canada, for clinical sensibility and with a target time to completion of $5 \mathrm{~min}$. The survey was structured using a web-based survey platform (FluidSurveys). Research ethics board approval was sought as required by lead investigators for each country that participated in the survey.

\section{Survey content}

The survey presented a typical patient with early septic shock in the ED (see survey, online supplementary appendix 1). This patient was introduced as a 55 -year-old $70 \mathrm{~kg}$ female who had just arrived in the ED with suspected septic shock. She was confused, with a blood pressure of $70 / 30$, heart rate $135 \mathrm{bpm}$, respiratory rate of 25 breaths per minute, temperature $39.5^{\circ} \mathrm{C}$ and oxygen saturation of $96 \%$ on $3 \mathrm{~L}$ by nasal prongs. She had already received a total of $1 \mathrm{~L}$ of normal saline over 15 min in the ED.

Respondents were then asked a series of questions: the first was to document the quantity and rapidity of fluid administration, and the second question examined the type of resuscitation fluids that they would use in a 'typical' and an 'ideal' situation to resuscitate the patient described above. An 'ideal' situation was proposed for respondents to ascertain the fluid type given that a physician may wish to give a fluid, but that fluid may not be readily available to them in practice (eg, fluid not stocked or immediately available in the department). For each of these questions, respondents answered on the basis of a five-point Likert scale (ie, never, rarely, sometimes, often, always). For the type of resuscitation fluid question (survey questions 2a and 2b), Ringer's solutions (ie, Ringer's lactate, Ringer's acetate and Hartmann's solutions) were bundled together as one 
response option, reflecting their biochemical similarity ${ }^{13}$ and reducing respondent question burden.

To inform the design of an early septic shock fluid resuscitation trial comparing $5 \%$ albumin to a crystalloid fluid on the primary outcome of 90-day mortality, we asked respondents to provide their views on an estimate of the MCID between the fluid intervention and control arms that would be required to inform their practice (response options: 1\%, 2.5\%, 5\%, $7.5 \%$ and $10 \%$ ). Two further questions were posed to determine the perceived importance of (response options: not at all important, not very important, somewhat important, important, very important) and their willingness to enrol patients into such a trial (response options: yes, no).

We also documented respondents' primary specialty and their practice experience in emergency medicine and/or critical care.

\section{Survey data collection and analysis}

All data were collected electronically through FluidSurveys (Ottawa, Ontario, Canada) and were housed and managed on FluidSurveys' secure servers. Prior to analysis, raw data were exported to Microsoft Excel (V.2010, Redmond, Washington, USA) for cleaning and then exported to SAS (V.9.2, by SAS Institute, Cary, North Carolina, USA) for analysis.

All data are presented with numbers and proportions for dichotomous and categorical variables, and with means and SDs or medians and IQRs for continuous variables, as appropriate. Missing responses were not imputed. The five-point Likert scale responses were combined into 'often or always', 'sometimes' and 'rarely or never' for purposes of data presentation. The data for all respondents were also described according to whether respondents were critical care or emergency medicine physicians. No sample size calculation was conducted a priori since main survey intent was to be descriptive. Post hoc, we calculated absolute differences (ADs) in proportions and 95\% CIs between typical and ideal fluid use for all respondents and by primary specialty (critical care physicians and emergency physicians), respectively. Differences in proportions with $95 \%$ CIs for emergency and critical care physicians for typical and ideal fluid were also calculated.

\section{RESULTS}

\section{Study sample}

A total of 1139 physicians responded to the survey; 16 respondents were not emergency or critical care physicians, a further 15 did not provide care for adult patients with septic shock, and 11 physicians did not respond to one $(n=10)$ or both $(n=1)$ of these questions. Thus, a total of 1097 physicians' responses were included in the final results. Of these, $64 \%(n=702)$ were from the UK, $26 \%(\mathrm{n}=290)$ were from Canada and the remaining $10 \%$ $(\mathrm{n}=105)$ were from Saudi Arabia $(6.6 \%, \mathrm{n}=72)$ and Scandinavia $(3.0 \%, \mathrm{n}=33)$.

\section{Demographics and training}

A total of $90 \% \quad(n=985)$ of physicians responded to the primary specialty question. Of these responses, $45.5 \%$ $(n=448)$ of physicians indicated that their primary specialty was emergency medicine. The average number of years spent in clinical practice was $10(\mathrm{SD}=8)$.

\section{Quantity and rapidity of administration of resuscitation fluids}

When we asked physicians about the quantity of resuscitation fluid that they would typically administer at a time to our hypothetical patient with early septic shock in the ED, the most common answer was $1 \mathrm{~L}$ of fluid $(46.9 \%, \mathrm{n}=499)$, followed by $500 \mathrm{~mL}(32.0 \%, \mathrm{n}=340$; see table 1$)$. When examined by primary specialty, $1 \mathrm{~L}(62.3 \%, \mathrm{n}=279)$ and $500 \mathrm{~mL}(41.5 \%, \mathrm{n}=223)$ were the most frequent responses for emergency and critical care physicians, respectively. Most physicians $(63 \%, \mathrm{n}=671)$ stated that they would administer the fluid challenges as quickly as possible; this response remained the most frequent when the data were examined by emergency and critical care physicians (73.2\%, $\mathrm{n}=328$ and $56.4 \%, \mathrm{n}=303$, respectively).

Type of resuscitation fluid typically and ideally administered Normal saline and Ringer's solutions were used typically 'often' or 'always' for early septic shock resuscitation

Table 1 Quantity and rapidity of fluid resuscitation by all respondents, critical care and emergency physicians

\begin{tabular}{|c|c|c|c|}
\hline \multicolumn{2}{|c|}{$\begin{array}{l}\text { Quantity n (\%) } \\
(n=1064)\end{array}$} & \multicolumn{2}{|l|}{$\begin{array}{l}\text { Rapidity n (\%) } \\
(n=1065)\end{array}$} \\
\hline \multicolumn{4}{|c|}{ All respondents } \\
\hline $100 \mathrm{~mL}$ & $2(0.2)$ & $5 \mathrm{~min}$ & $66(6.2)$ \\
\hline $250 \mathrm{~mL}$ & $123(11.6)$ & $10 \mathrm{~min}$ & $98(9.2)$ \\
\hline $500 \mathrm{~mL}$ & $340(32.0)$ & $15 \mathrm{~min}$ & $131(12.3$ \\
\hline $750 \mathrm{~mL}$ & $9(0.8)$ & $30 \mathrm{~min}$ & $81(7.6)$ \\
\hline $1000 \mathrm{~mL}$ & 499 (46.9) & 1 hour & $18(1.7)$ \\
\hline Other & $91(8.6)$ & $\begin{array}{l}\text { As quickly as } \\
\text { possible }\end{array}$ & $671(63.0$ \\
\hline$(n=537)$ & & $(n=537)$ & \\
\hline \multicolumn{4}{|c|}{ Critical care physicians } \\
\hline $100 \mathrm{~mL}$ & $2(0.4)$ & $5 \mathrm{~min}$ & $45(8.4)$ \\
\hline $250 \mathrm{~mL}$ & $86(16.0)$ & $10 \mathrm{~min}$ & $64(11.9$ \\
\hline $500 \mathrm{~mL}$ & $223(41.5)$ & $15 \mathrm{~min}$ & $75(14.0$ \\
\hline $750 \mathrm{~mL}$ & $6(1.1)$ & $30 \mathrm{~min}$ & $42(7.8)$ \\
\hline $1000 \mathrm{~mL}$ & $194(36.1)$ & 1 hour & $8(1.5)$ \\
\hline Other & $26(4.8)$ & $\begin{array}{l}\text { As quickly as } \\
\text { possible }\end{array}$ & $303(56.4$ \\
\hline$(n=448)$ & & $(n=448)$ & \\
\hline \multicolumn{4}{|c|}{ Emergency physicians } \\
\hline $100 \mathrm{~mL}$ & $0(0)$ & $5 \min$ & $12(2.7)$ \\
\hline $250 \mathrm{~mL}$ & $21(4.7)$ & $10 \mathrm{~min}$ & $25(5.6)$ \\
\hline $500 \mathrm{~mL}$ & $90(20.1)$ & $15 \mathrm{~min}$ & $43(9.6)$ \\
\hline $750 \mathrm{~mL}$ & $3(0.7)$ & $30 \mathrm{~min}$ & $35(7.8)$ \\
\hline $1000 \mathrm{~mL}$ & 279 (62.3) & 1 hour & $5(1.1)$ \\
\hline Other & 55 (12.3) & $\begin{array}{l}\text { As quickly as } \\
\text { possible }\end{array}$ & 328 (73.2 \\
\hline
\end{tabular}




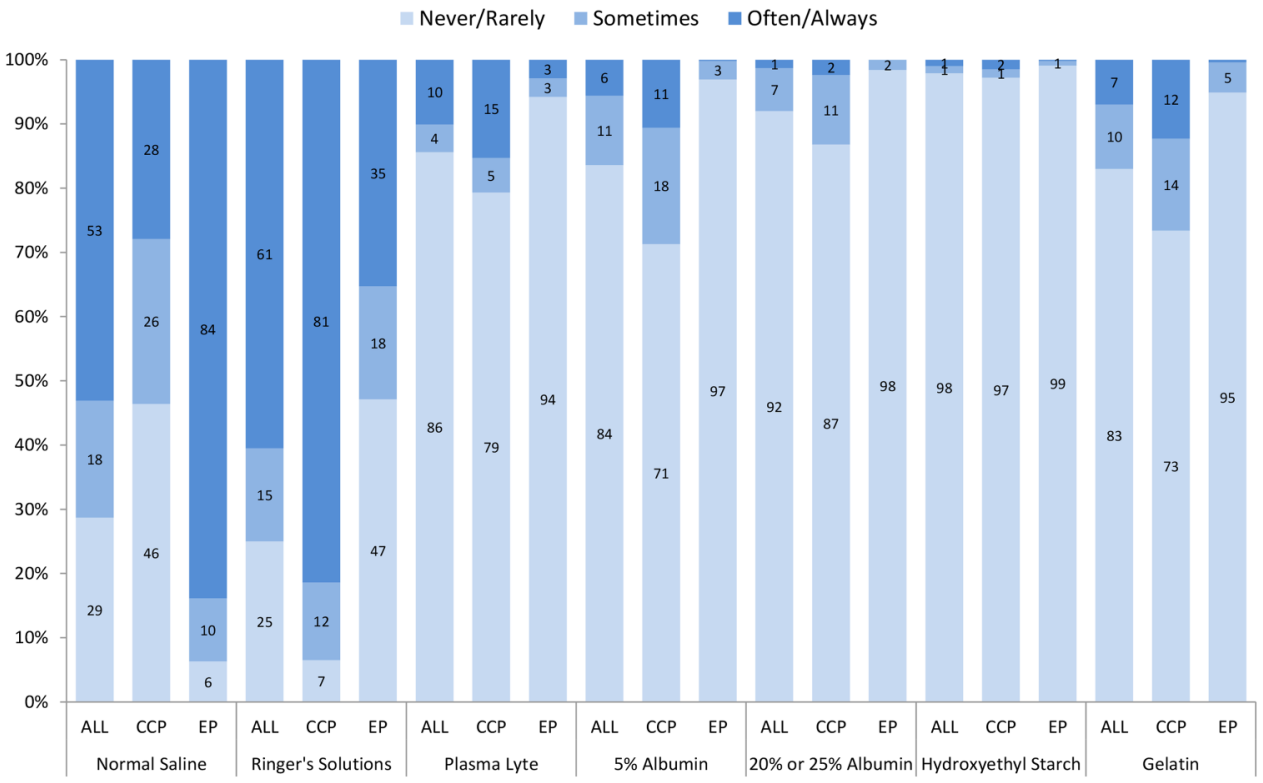

Figure 1 The $\mathrm{Y}$-axis depicts the proportion of respondents that answered never/rarely, sometimes or often/always to each typical resuscitation fluid type. The $\mathrm{X}$-axis includes each typical resuscitation fluid type according to all respondents, emergency physicians and critical care physicians. The response for Ringer's solutions could reflect typical use of Ringer's lactate, Ringer's acetate or Hartmann's solutions, since these solutions were bundled into one response option in survey question 2a. ALL, all respondents; CCP, critical care physicians; EP, emergency physicians.

$53.1 \%(\mathrm{n}=556)$ and $60.5 \%(\mathrm{n}=632)$ of the time, respectively (see figure 1 and table 2). In contrast, respondents infrequently used Plasma-Lyte $(10.1 \%, \mathrm{n}=106), 5 \%$ albumin $(5.6 \%, \mathrm{n}=59), 20-25 \%$ albumin $(1.3 \%, \mathrm{n}=14)$ and gelatin $(7.0 \%, \mathrm{n}=73)$ 'often' or 'always' in early resuscitative efforts. Only $1.0 \% \quad(n=10)$ of respondents indicated that they would use HES 'often' or 'always' in the resuscitative phase of septic shock.

When asked about the use of these fluids in the ideal setting where they would be immediately available, use of Plasma-Lyte and 5\% albumin 'often' or 'always' increased the most (Plasma-Lyte from $10.1 \% \quad(\mathrm{n}=106)$ to $25.3 \%(\mathrm{n}=264 ; \mathrm{AD}=-15.2 \%$; $95 \% \mathrm{CI}-17.5 \%$ to $-12.9 \%)$ and $5 \%$ albumin from $5.6 \%(\mathrm{n}=59)$ to $12.4 \% \quad(\mathrm{n}=129$; $\mathrm{AD}=-6.7 \%$; $95 \%$ CI $-8.3 \%$ to $-5.0 \%$; see figure 2 and online supplementary table S1)).

When the typical use of crystalloid fluids was examined by primary specialty, emergency physicians indicated that they would use normal saline 'often' or 'always' $83.9 \%$ ( $\mathrm{n}=376)$, in contrast to critical care physicians, who said that they would use saline $27.9 \% \quad(n=150$; $\mathrm{AD}=56.0 \%$; $95 \%$ CI $50.9 \%$ to $61.1 \%$; see figure 1 and online supplementary table S1). In the ideal setting, where these fluids would be immediately available, the two fluid-type responses that increased the most for emergency physicians were Ringer's solutions from $35.3 \% \quad(\mathrm{n}=158)$ to $45.1 \% \quad(\mathrm{n}=202 ; \mathrm{AD}=-9.8 ; 95 \%$ CI -13.3 to -6.4$)$ and Plasma-Lyte from $2.9 \%(\mathrm{n}=13)$ to $11.4 \%(\mathrm{n}=51 ; \mathrm{AD}=-8.5 ; 95 \%$ CI -11.2 to -5.8 ; see figure 2, online supplementary table S1). The two fluid- type responses that increased the most in the ideal setting for critical care physicians were Plasma-Lyte (from $15.3 \%(\mathrm{n}=82)$ to $36.5 \%(\mathrm{n}=196), \mathrm{AD}=-21.2 ; 95 \%$ CI -24.9 to -17.6 ) and $5 \%$ albumin (from $10.6 \%$ $(\mathrm{n}=57)$ to $20.5 \% \quad(\mathrm{n}=110), \mathrm{AD}=-9.9 ; 95 \%$ CI -12.6 to $-7.1)$.

A summary of typical and ideal fluid use by country is provided in online supplementary table S2 and figures S1 and S2, respectively.

Views on a future early septic shock fluid resuscitation trial Most respondents indicated that the MCID for a future trial comparing 5\% albumin and a crystalloid fluid on 90-day mortality for early septic shock that would be required to maintain or change their practice was $5 \%$ $(53.6 \%, 539 / 1005)$. Respondents also indicated that a large randomised controlled trial comparing 5\% albumin to a crystalloid fluid with a primary outcome of 90-day mortality was important to conduct as $88.4 \%$ (896/1014) of respondents indicated that the trial was somewhat important $(24.0 \%, 243 / 1014)$, important $(39.4 \%, 400 / 1014)$ or very important $(25 \%, 253 / 1014)$. Furthermore, $84.4 \%(851 / 1008)$ of respondents indicated that they would be willing to enrol patients into such a future clinical trial.

\section{DISCUSSION}

Results of our multicountry survey suggest that emergency and critical care physicians who assess and 


\begin{tabular}{|c|c|c|c|c|c|c|c|c|}
\hline \multirow[b]{2}{*}{ Type } & \multicolumn{4}{|c|}{ Typically administered } & \multicolumn{4}{|c|}{ Ideally administered } \\
\hline & $\begin{array}{l}\text { Number } \\
\text { Respondents }\end{array}$ & $\begin{array}{l}\text { Never/rarely } \\
\text { n (\%) }\end{array}$ & $\begin{array}{l}\text { Sometimes } \\
\text { n (\%) }\end{array}$ & $\begin{array}{l}\text { Often/always } \\
\text { n (\%) }\end{array}$ & $\begin{array}{l}\text { Number } \\
\text { Respondents }\end{array}$ & $\begin{array}{l}\text { Never/rarely } \\
\text { n (\%) }\end{array}$ & $\begin{array}{l}\text { Sometimes } \\
\text { n (\%) }\end{array}$ & $\begin{array}{l}\text { Often/always } \\
\text { n (\%) }\end{array}$ \\
\hline \multicolumn{9}{|l|}{ All respondents } \\
\hline Normal saline & $(n=1047)$ & $300(28.7)$ & $191(18.2)$ & $556(53.1)$ & $(n=1045)$ & $384(36.7)$ & $165(15.8)$ & $496(47.5)$ \\
\hline Ringer's solutions & $(n=1045)$ & $261(25.0)$ & $152(14.5)$ & $632(60.5)$ & $(n=1044)$ & $232(22.2)$ & $141(13.5)$ & 671 (64.3) \\
\hline Plasma-Lyte & $(n=1045)$ & $894(85.6)$ & $45(4.3)$ & $106(10.1)$ & $(n=1043)$ & $716(68.7)$ & $63(6.0)$ & $264(25.3)$ \\
\hline $5 \%$ albumin & $(n=1045)$ & $873(83.5)$ & $113(10.8)$ & $59(5.6)$ & $(n=1044)$ & 740 (70.9) & $175(16.8)$ & $129(12.4)$ \\
\hline $20 \%$ or $25 \%$ albumin & $(n=1044)$ & $960(92.0)$ & $70(6.7)$ & $14(1.3)$ & $(n=1043)$ & 911 (87.3) & $101(9.7)$ & $31(3.0)$ \\
\hline Hydroxyethyl starch & $(n=1044)$ & $1023(98.0)$ & $11(1.1)$ & $10(1.0)$ & $(n=1044)$ & $1017(97.4)$ & $15(1.4)$ & $12(1.1)$ \\
\hline Gelatin & $(n=1045)$ & $868(83.1)$ & $104(10.0)$ & $73(7.0)$ & $(n=1044)$ & $903(86.5)$ & $82(7.9)$ & $59(5.7)$ \\
\hline \multicolumn{9}{|l|}{ Critical care physicians } \\
\hline Normal saline & $(n=537)$ & $249(46.4)$ & $138(25.7)$ & $150(27.9)$ & $(n=537)$ & $300(55.9)$ & $114(21.2)$ & $123(22.9)$ \\
\hline Ringer's solutions & $(n=537)$ & $35(6.5)$ & $65(12.1)$ & 437 (81.4) & $(n=537)$ & $51(9.5)$ & $56(10.4)$ & $430(80.1)$ \\
\hline Plasma-Lyte & $(n=537)$ & $426(79.3)$ & $29(5.4)$ & $82(15.3)$ & $(n=537)$ & 297 (55.3) & $44(8.2)$ & $196(36.5)$ \\
\hline $5 \%$ albumin & $(n=537)$ & $383(71.3)$ & $97(18.1)$ & $57(10.6)$ & $(n=537)$ & $310(57.7)$ & $117(21.8)$ & $110(20.5)$ \\
\hline $20 \%$ or $25 \%$ albumin & $(n=537)$ & $466(86.8)$ & $58(10.8)$ & $13(2.4)$ & $(n=537)$ & 442 (82.3) & 71 (13.2) & $24(4.5)$ \\
\hline Hydroxyethyl starch & $(n=537)$ & $522(97.2)$ & 7 (1.3) & $8(1.5)$ & $(n=537)$ & $521(97.0)$ & 7 (1.3) & $9(1.7)$ \\
\hline Gelatin & $(n=537)$ & $394(73.4)$ & $77(14.3)$ & $66(12.3)$ & $(n=537)$ & $426(79.3)$ & $58(10.8)$ & $53(9.9)$ \\
\hline \multicolumn{9}{|l|}{ Emergency physicians } \\
\hline Normal saline & $(n=448)$ & $28(6.3)$ & $44(9.8)$ & 376 (83.9) & $(n=448)$ & $61(13.6)$ & $41(9.2)$ & 346 (77.2) \\
\hline Ringer's solutions & $(n=448)$ & $211(47.1)$ & 79 (17.6) & $158(35.3)$ & $(n=448)$ & 170 (37.9) & $76(17.0)$ & $202(45.1)$ \\
\hline Plasma-Lyte & $(n=448)$ & $422(94.2)$ & $13(2.9)$ & $13(2.9)$ & $(n=448)$ & $381(85.0)$ & $16(3.6)$ & $51(11.4)$ \\
\hline $5 \%$ albumin & $(n=448)$ & 434 (96.9) & $13(2.9)$ & $1(0.2)$ & $(n=448)$ & $384(85.7)$ & $47(10.5)$ & $17(3.8)$ \\
\hline $20 \%$ or $25 \%$ albumin & $(n=448)$ & $441(98.4)$ & 7 (1.6) & $0(0)$ & $(n=448)$ & $423(94.4)$ & $20(4.5)$ & $5(1.1)$ \\
\hline Hydroxyethyl starch & $(n=448)$ & $444(99.1)$ & $3(0.7)$ & $1(0.2)$ & $(n=448)$ & 437 (97.5) & $8(1.8)$ & $3(0.7)$ \\
\hline Gelatin & $(n=448)$ & 425 (94.9) & $21(4.7)$ & $2(0.4)$ & $(n=448)$ & $424(94.6)$ & $21(4.7)$ & $3(0.7)$ \\
\hline
\end{tabular}




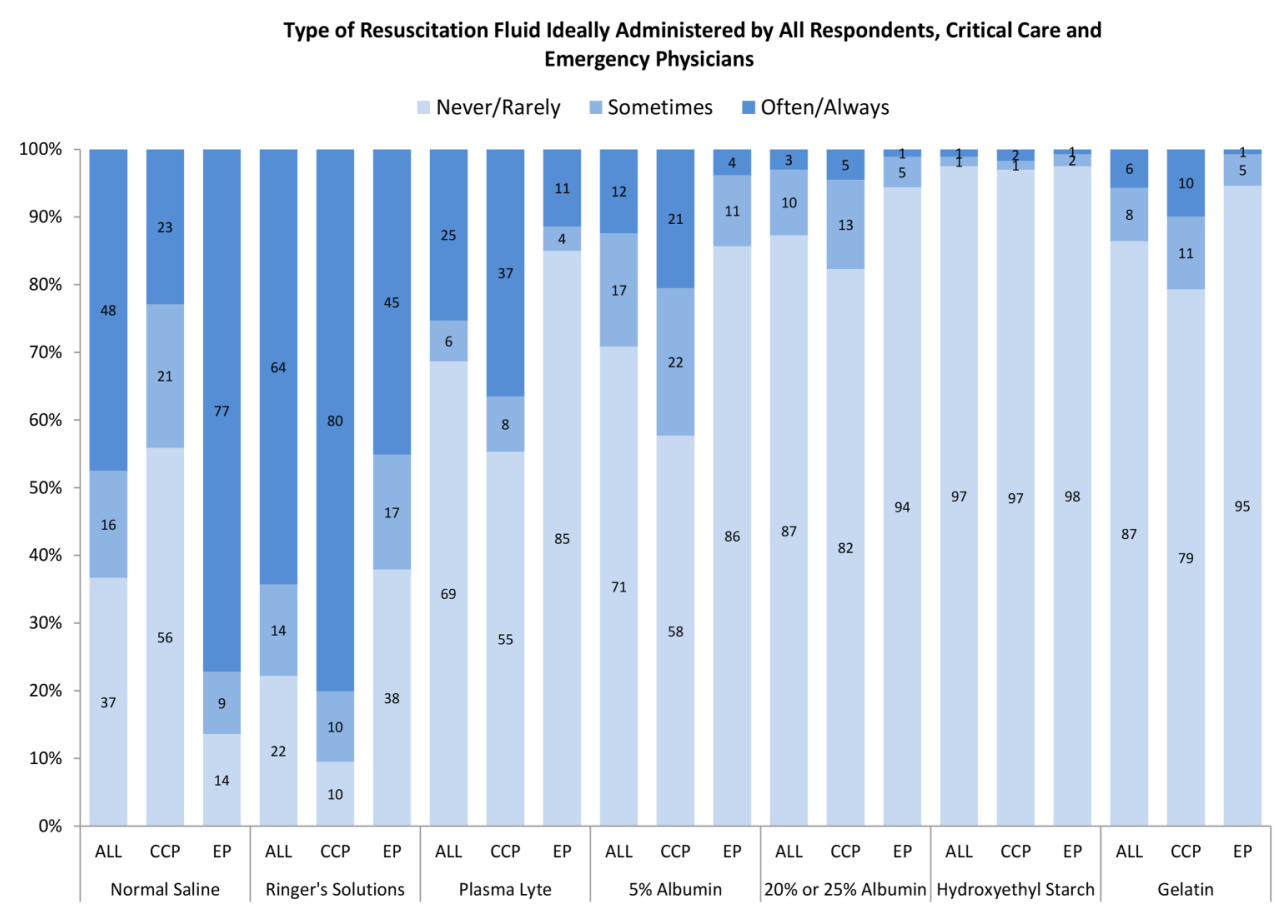

Figure 2 The $\mathrm{Y}$-axis depicts the proportion of respondents that answered never/rarely, sometimes or often/always to each ideal resuscitation fluid type. The $\mathrm{X}$-axis includes each ideal resuscitation fluid type according to all respondents, emergency physicians and critical care physicians. The response for Ringer's solutions could reflect ideal use of Ringer's lactate, Ringer's acetate or Hartmann's solutions since these solutions were bundled into one response option in survey question $2 \mathrm{~b}$. ALL, all respondents; CCP, critical care physicians; EP, emergency physicians.

manage adult patients in the early resuscitative phase of septic shock prefer that fluid challenges (at least $500 \mathrm{~mL}$ ) be administered as quickly as possible. When examined by primary specialty, critical care physicians indicated a preference to use Ringer's solutions compared with emergency physicians who indicated a preference to use normal saline. Although the reported use of Plasma-Lyte was infrequent, our survey data suggest that both emergency and critical care physicians would use more of this crystalloid fluid if it was readily available to them. Use of HES fluid was uncommon and the reported use of albumin (5\% or $20-25 \%)$ was infrequent, although critical care physicians also indicated that they would use albumin more frequently if it was immediately available to them.

An abundance of observational evidence from large propensity-matched cohort studies in the surgical ${ }^{14}{ }^{15}$ and critically ill ${ }^{16}$ populations, and a prospective sequential period study ${ }^{17}$ in the critically ill suggest that highchloride fluids (eg, normal saline) may be associated with excess mortality compared with lower chloride fluids such as Ringer's solutions or Plasma-Lyte. In addition, normal saline resuscitation has been associated with the subsequent use of renal replacement therapy, increased postoperative infections and prolonged length of stay in hospital. ${ }^{14-17} \mathrm{~A}$ recently published pilot trial examined normal saline versus Plasma-Lyte for fluid resuscitation in the intensive care unit. ${ }^{18}$ Investigators did not detect an increased risk of acute kidney injury or failure, or an increased risk of requirement for renal replacement therapy with normal saline. However, the study was underpowered for these clinical outcomes and a larger trial with death as the primary end point is now planned (NCT02721654). Both our survey and a similar survey conducted in Scotland ${ }^{19}$ suggest that emergency physicians prefer using normal saline, while critical care physicians prefer Ringer's solutions in septic shock. The variability in stated practice between emergency and critical care physicians that was evident in our survey may reflect an absence of high-quality evidence to support the preference of either of these fluids, although a recent network meta-analysis of randomised controlled fluid trials in sepsis found that balanced crystalloids such as Ringer's or Plasma-Lyte as compared with normal saline were associated with a reduced odds of death. ${ }^{20}$ However, since the reported use of Ringer's solutions and Plasma-Lyte further increased when presented with an 'ideal' but still theoretical scenario in our survey, lack of availability of these fluids or unit-specific policies or protocols ${ }^{21}$ may contribute to the reported practice variability we identified.

Very few emergency and critical care physicians indicated that they would use HES boluses in the early resuscitative phase of septic shock. This contrasts sharply to a septic shock resuscitation survey from 2004 in which Canadian critical care physicians reported that they would use HES fluids for early septic shock resuscitation $51 \%$ of the time. In the European intensive care unit fluid challenge observational study conducted in 2013, HES use accounted for only $10.8 \%$ of all fluid 
challenges in the study. ${ }^{21}$ This apparent change in practice is most likely related to high-quality evidence from randomised controlled trials and systematic reviews in the past decade that now confirm that starch fluids increase the risk of death and the use of renal replacement therapy in patients with severe sepsis and septic shock. ${ }^{6} 79$

According to our survey results, the use of albumin in the early septic shock setting also remains infrequent despite the SAFE (A Comparison of Albumin to Saline for Fluid Resuscitation in the Intensive Care Unit) severe sepsis subgroup analysis that suggested that $4 \%$ albumin compared with normal saline was associated with a significant reduction in 28-day mortality. After the conduct of this survey in 2014, the ALBIOS trial (Albumin Replacement for Patients with Severe Sepsis and Septic Shock) which compared 20\% albumin with crystalloids versus crystalloids alone for patients with severe sepsis and septic shock was published. The ALBIOS trial found a mortality benefit at 90 days for $20 \%$ albumin in a post hoc analysis of patients with septic shock but not in those with severe sepsis. ${ }^{12}$ If practice was influenced by that trial, it is possible that the albumin responses in our survey under-represent current use in early septic shock.

This survey has several weaknesses. A denominator could not be calculated to ascertain a response proportion because of the variable methods we used to distribute the survey. Although we obtained responses from $\sim 1000$ critical care and emergency medicine physicians from Canada, the UK, Saudi Arabia and Scandinavia, we cannot confirm that the responses generated are representative of the countries or regions. Resuscitation questions were asked in relation to one hypothetical early septic shock scenario and, as such, it is not possible to comment on fluid resuscitation practices, according to physician characteristics, for patients in the later phase of septic shock or with specific physiological characteristics (eg, hypoalbuminaemia), or chronic morbidities. However, this survey was large ( 1000 responses), and it includes the stated preferences of critical care and emergency medicine physicians, which are divergent with regard to the quantity and type of resuscitation fluid used for early septic shock resuscitation. Although answers to questions related to other aspects of septic shock management were not obtained, they provide robust information regarding the fluid resuscitation practices of a wide variety of physicians managing patients in the early resuscitative phase of septic shock. Furthermore, the survey was designed to be brief and take $<5$ min to complete to maximise responses to each question. That goal was achieved, since at least $95 \%$ of respondents answered each of the resuscitation questions.

In summary, in the resuscitative phase of septic shock, emergency and critical care physician practices as stated in this survey are to administer volumes of resuscitation fluid most commonly in the range of $500-1000 \mathrm{~mL}$ at a time. It is important to note that these volumes are within the current surviving sepsis resuscitation guidelines that recommend a minimum achievement of $30 \mathrm{~mL} / \mathrm{kg}$ in the early hours of resuscitation since our aim was to elicit details of how much bolused resuscitation fluid would be administered at a time during early septic shock. ${ }^{1}$ Although normal saline and Ringer's solutions are the two most common crystalloid fluids, stated preferences differ between emergency and critical care physicians. Most physicians support a future trial of albumin compared with crystalloid fluid in the early phase of septic shock.

\section{Author affiliations}

${ }^{1}$ Department of Medicine (Division of Critical Care), University of Ottawa, Ottawa, Ontario, Canada

${ }^{2}$ The Ottawa Hospital Research Institute, Ottawa, Ontario, Canada

${ }^{3}$ Department of Epidemiology and Community Medicine, University of Ottawa, Ottawa, Ontario, Canada

${ }^{4}$ Department of Emergency Medicine, University of Alberta, Edmonton, Alberta, Canada

${ }^{5}$ School of Public Health, University of Alberta, Edmonton, Alberta, Canada ${ }^{6}$ Department of Anaesthetics, Critical Care, and Pain Medicine, University of Edinburgh, Edinburgh, UK

${ }^{7}$ Department of Emergency Medicine, Royal Infirmary of Edinburgh, Edinburgh, UK

${ }^{8}$ King Saud Bin Abdulaziz University for Health Sciences and King Abdullah International Medical Research Center, Riyadh, Saudi Arabia

${ }^{9}$ Department of Intensive Care, Ringshospitalet, Copenhagen, Denmark

${ }^{10}$ Department of Anaesthesia, Pain Medicine and Intensive Care, Imperial

College London, London, UK

${ }^{11}$ Department of Surgery, University of Toronto, Toronto, Ontario, Canada

${ }^{12}$ Departments of Medicine and Clinical Epidemiology and Biostatistics,

McMaster University, Hamilton, Ontario, Canada

${ }^{13}$ Department of Medicine and Thrombosis and Atherosclerosis Research

Institute, McMaster University, Hamilton, Ontario, Canada

${ }^{14}$ Faculty of Medicine and Dentistry, Division of Critical Care Medicine, University of Alberta, Edmonton, Canada

${ }^{15}$ Department of Critical Care Medicine, Dalhousie University, Halifax, Nova Scotia, Canada

${ }^{16}$ Division of Critical Care Medicine, Department of Anesthesiology and Critical Care Medicine, Université Laval, Québec City, Québec, Canada

${ }^{17}$ Population Health and Optimal Health Practice Research Unit (TraumaEmergency - Critical Care Medicine), CHU de Québec Research Center, CHU de Québec (Hôpital de l'Enfant-Jésus), Laval, Québec City, Québec, Canada

${ }^{18}$ CancerCare Manitoba, Winnipeg, Manitoba, Canada

Twitter Follow Anthony Gordon at @agordonICU

Acknowledgements The authors would like to acknowledge the Canadian Critical Care Society, the Intensive Care Foundation (UK), the Royal College of Emergency Medicine (UK) and the King Abdullah International Medical Research Centre for their assistance in contacting emergency and critical care physicians through their respective membership lists. BHR is

supported by the Canadian Institutes of Health Research (CIHR) as a Tier I Canada Research Chair in Evidence-based Emergency Medicine through the Government of Canada (Ottawa, Ontario, Canada). AT and RZ are recipients of CIHR new investigator awards, SMB is supported by CIHR as a Tier II Canada Research Chair in Critical Care Nephrology and DC is supported by CIHR as a Tier II Canada Research Chair in Critical Care. The authors would like to thank Francois Lauzier from the Canadian Critical Care Trials Group for a critical review of this manuscript, Tinghua Zhang from the Ottawa Hospital Research Institute (OHRI) for collating the data and performing the statistical analyses, the Centre for Transfusion Research at the OHRI for their in-kind study support, and Marnie Gordon for her administrative support.

Contributors LM, DF, BHR, TSW, AG, AP, YA and JM conceived the survey design. LM drafted the manuscript and all authors contributed to 
interpretation of the data and critical revisions of the manuscript. All authors have given permission to submit this manuscript for publication.

Funding This research received no specific grant from any funding agency in the public, commercial or not-for-profit sectors.

Competing interests FluidSurveys' involvement in the project was limited to providing the secure platform that allowed the research team to collect data. AP has received grant support from CSL Behring and Fresenius Kabi and LM has received grant support from CSL Behring, all of which is outside of this submitted work. SMB has consulted for Baxter Healthcare Corp.

Ethics approval Ottawa Health Sciences Network Research Ethics Board.

Provenance and peer review Not commissioned; externally peer reviewed.

Data sharing statement No additional data are available.

Open Access This is an Open Access article distributed in accordance with the Creative Commons Attribution Non Commercial (CC BY-NC 4.0) license, which permits others to distribute, remix, adapt, build upon this work noncommercially, and license their derivative works on different terms, provided the original work is properly cited and the use is non-commercial. See: http:// creativecommons.org/licenses/by-nc/4.0/

\section{REFERENCES}

1. Dellinger RP, Levy MM, Rhodes A, et al. Surviving Sepsis Campaign: international guidelines for management of severe sepsis and septic shock, 2012. Intensive Care Med 2013;39:165-228.

2. Maitland K, Kiguli S, Opoka RO, et al. Mortality after fluid bolus in African children with severe infection. $N$ Engl J Med 2011;364:2483-95.

3. Mclntyre LA, Hébert PC, Fergusson D, et al. A survey of Canadian intensivists' resuscitation practices in early septic shock. Crit Care 2007; $11:$ R74.

4. Finfer S, Liu B, Taylor C, et al. Resuscitation fluid use in critically ill adults: an international cross-sectional study in 391 intensive care units. Crit Care 2010;14:R185.

5. Myburgh JA, Finfer S, Bellomo R, et al. Hydroxyethyl starch or saline for fluid resuscitation in intensive care. $N$ Engl $J$ Med 2012;367:1901-11.

6. Perner A, Haase N, Guttormsen AB, et al. Hydroxyethyl starch 130/ 0.42 versus Ringer's acetate in severe sepsis. $N$ Engl J Med 2012;367:124-34.

7. Haase N, Perner A, Hennings LI, et al. Hydroxyethyl starch 130/ 0.38-0.45 versus crystalloid or albumin in patients with sepsis: systematic review with meta-analysis and trial sequential analysis. BMJ 2013;346:f839.
8. Gattas DJ, Dan A, Myburgh J, et al. Fluid resuscitation with $6 \%$ hydroxyethyl starch (130/0.4) in acutely ill patients: an updated systematic review and meta-analysis. Anesth Analg 2012;114:159-69.

9. Zarychanski R, Abou-Setta AM, Turgeon AF, et al. Association of hydroxyethyl starch administration with mortality and acute kidney injury in critically ill patients requiring volume resuscitation: a systematic review and meta-analysis. JAMA 2013;309:678-88.

10. Patel A, Laffan MA, Waheed U, et al. Randomised trials of human albumin for adults with sepsis: systematic review and meta-analysis with trial sequential analysis of all-cause mortality. BMJ 2014;349: g4561.

11. Finfer S, McEvoy S, Bellomo R, et al. Impact of albumin compared to saline on organ function and mortality of patients with severe sepsis. Intensive Care Med 2011;37:86-96.

12. Caironi $\mathrm{P}$, Tognoni $\mathrm{G}$, Masson $\mathrm{S}$, et al. Albumin replacement in patients with severe sepsis or septic shock. N Engl J Med 2014;370:1412-21.

13. Reddy S, Weinberg L, Young P, et al. Crystalloid fluid therapy. Crit Care 2016;20:59.

14. Shaw AD, Bagshaw SM, Goldstein SL, et al. Major complications, mortality, and resource utilization after open abdominal surgery: $0.9 \%$ saline compared to Plasma-Lyte. Ann Surg 2012;255: 821-9.

15. McCluskey SA, Karkouti K, Wijeysundera D, et al. Hyperchloremia after noncardiac surgery is independently associated with increased morbidity and mortality: a propensity-matched cohort study. Anesth Analg 2013;117:412-21.

16. Raghunathan K, Shaw A, Nathanson B, et al. Association between the choice of IV crystalloid and in-hospital mortality among critically ill adults with sepsis*. Crit Care Med 2014;42:1585-91.

17. Yunos NM, Bellomo R, Hegarty C, et al. Association between a chloride-liberal vs chloride-restrictive intravenous fluid administration strategy and kidney injury in critically ill adults. JAMA 2012;308:1566-72.

18. Young P, Bailey M, Beasley R, et al., SPLIT Investigators; ANZICS CTG. Effect of a buffered crystalloid solution vs saline on acute kidney injury among patients in the intensive care unit: the SPLIT randomized clinical trial. JAMA 2015;314:1701-10.

19. Jiwaji Z, Brady S, Mclntyre LA, et al. Emergency department management of early sepsis: a national survey of emergency medicine and intensive care consultants. Emerg Med $J$ 2014;31:1000-5.

20. Rochwerg B, Alhazzani W, Sindi A, et al. Fluid resuscitation in sepsis: a systematic review and network meta-analysis. Ann Intern Med 2014;161:347-55.

21. Cecconi M, Hofer C, Teboul JL, et al, ESICM Trial Group. Fluid challenges in intensive care: the FENICE study: a global inception cohort study. Intensive Care Med 2015;41:1529-37. 